\title{
JOGOS VIRTUAIS E LUDICIDADE: UMA ANÁLISE DO JOGO MINECRAFT
}

\section{VIRTUAL GAMES ANDLUDICITY: A MINECRAFT GAME REVIEW}

\author{
Marsiel Pacífico ${ }^{1}$ \\ Universidade Estadual de Mato Grosso do Sul - UEMS \\ Marilúcia Antônia de Resende Peroza² \\ Universidade de Ponta Grossa - UEPG \\ Mariane Aparecida Gomes Galvão3 \\ Universidade de Ponta Grossa - UEPG
}

\section{Resumo}

O presente trabalho tem como objetivo trazer uma análise entre o jogo real, o jogo virtual e a ludicidade. Sendo assim, procura-se compreender o que há de lúdico no jogo virtual, assim como as diferenças e semelhanças que este apresenta em relação ao jogo real, juntamente com as contribuições que ambos oferecem para o desenvolvimento da criança, uma vez que esses elementos estão presentes ao longo da infância, fase esta em que o indivíduo está propício a adquirir novos conhecimentos e aguçar suas potencialidades. Inicia-se com o estudo bibliográfico dos conceitos de jogo, jogo lúdico e o jogo virtual, assim como suas características e semelhanças. Em seguida, tem-se o estudo de caso através da análise do jogo virtual Minecraft. Para tanto, utilizou-se vídeos de jogadores do referido game, que foram postados no portal Youtube, no qual analisou-se as interações e modos de brincar nesse espaço virtual específico a partir dos conceitos de jogo e ludicidade. Destaca-se que, ambos os jogos, virtual e real, têm semelhanças e divergências e que, em especial, o jogo virtual tem muita influência no processo de desenvolvimento da criança, tanto cognitivo, como motor e intelectual, tendo também presente a ludicidade, porém, é preciso que seja utilizado de forma equilibrada.

Palavras-chave: Jogos; Ludicidade; Minecraft.

\footnotetext{
1 Professor Adjunto da Universidade Estadual do Mato Grosso do Sul (UEMS) Campus Jardim. Doutor em Educação (2013-2017) na linha de pesquisa do PPGE/UFSCAR \&quot; Educação, Cultura e Subjetividade\&quot; Mestre em Educação (2010-2012) na linha de \&quot;Filosofia, História e Sociologia da Educação\&quot; pela Universidade Federal de São Carlos onde também graduou-se em Pedagogia (2006-2009).

2 Possui graduação em pedagogia pela Universidade de Minas Gerais (2001), mestrado em educação pela Pontifícia Universidade Católica do Paraná (2012) e doutorado em educação pela Pontifícia Universidade Católica do Paraná (2017). Atualmente é professora adjunta na Universidade Estadual de Ponta Grossa e líder do Grupo de Estudos, Pesquisa e Extensão em Educação Infantil (GEPEEDI).

${ }^{3}$ Graduada em Pedagogia pela Universidade Estadual de Ponta Grossa (UEPG).
} 


\section{Abstract}

The present work has as objective to bring an analysis on the real game, the virtual game and the ludicity, in order to understand what there is of ludicity in the virtual game and what the differences and similarities that presents in relation to the real game. As well as the contribution that both offer to the development of the child, since these elements are present throughout childhood, where the individual is propitious to acquire new knowledge and sharpen their potentialities. It begins with the bibliographic study of the concepts of game, game and play, virtual game, and the characteristics and similarities between them. Then the case study is performed from the analysis of the virtual game Minecraft.In order to do so, it was used the videos of players of said game, which were posted on the Youtube portal, in which the interactions and ways of playing in this specific virtual space were analyzed based on the concepts of game and ludicity.It should be stressed that both virtual and real games have similarities and divergences and that in particular the virtual game has much to contribute to the development process of the child, since they contribute to cognitive, motor and intellectual development, and that playability is present in virtual games as well, thus favoring this acquisition of developments, as long as it is used in a balanced way.

Keywords: Games; Ludicity; Minecraft.

\section{INTRODUÇÃO}

Os jogos e as brincadeiras ${ }^{4}$ são de grande importância para o desenvolvimento da criança, pois incentivam o seu desenvolvimento intelectual, cognitivo, social e emocional, estimulando o imaginário e a criatividade, proporcionando lazer e favorecendo a liberdade. Conforme Neves (2010),

O jogo seduz, é atrativo, porque desafia, permite que o indivíduo use os seus sentidos, use todas as suas habilidades para criar estratégias, para inventar planos, que abusam do raciocínio, da capacidade de resolver problemas, exige que o sujeito produza, crie, seja dinâmico (NEVES, 2010, s/p).

Existem muitos estudos sobre a criança e seu desenvolvimento, com temáticas e formas de aguçar esse processo, nos quais é possível identificar que o mesmo se dá por meio da ação lúdica, no envolvimento com os pares e com o simples ato de jogar. O jogo é algo fascinante, cativante, que enfeitiça o jogador e faz despertar sua imaginação, permitindo inventar papéis e fingir-se ser algo ou alguém. Está ligado diretamente à criança e ao favorecer de seu desenvolvimento cognitivo, motor e intelectual. Todavia, historicamente os jogos ficavam restritos ao mundo real. Com o advento das tecnologias podemos observar um novo espaço para o jogo: o mundo virtual.

\footnotetext{
${ }^{4}$ Conforme discussão realizada ao longo deste texto, o jogo, o brincar, a brincadeira, não podem ser conceituado de maneira definitiva. Há uma grande discussão em relação ao conceito referente a estes termos. Neste trabalho, entendemos jogo e brincadeira a partir desta distinção: o jogo como sendo uma atividade que se limita a regras e tem um objetivo final e a brincadeira como algo livre.
} 
Com o avanço da tecnologia, os jogos virtuais estão presentes cada vez mais cedo na vida das crianças, ocupando grande parte do tempo de sua infância. Usados e manipulados corretamente, estes podem ajudar, tornando-se um aliado no processo do desenvolvimento da criança. Caso contrário, torna-se vicioso e sem sentido para a criança, que acaba se perdendo no mundo virtual e deixando de viver completamente o mundo real, desencadeando até mesmo possíveis problemas de saúde, como a obesidade infantil.

Assim, este trabalho tem por objetivo buscar respostas e compreensões de conceitos, buscando sentido na relação entre o jogo real, o virtual e suas contribuições para o desenvolvimento infantil. Uma vez que ambos os jogos estão demasiadamente presentes entre as crianças, necessita-se assim ter um entendimento mais preciso de suas características e atribuições para a infância. Dessa maneira, surgem outras questões específicas a serem trabalhadas no decorrer desse trabalho, dentre elas: o conceito de jogo e suas características; surgimento dos jogos virtuais e sua evolução; motivo pelo qual o jogo virtual chama tanta atenção de seu público; e de que maneira ambos os jogos estão envolvidos como favorecedores do desenvolvimento infantil.

Inicialmente, a pesquisa será feita por estudo bibliográfico para compreender e analisar o conceito de jogo e ludicidade. Em seguida, a partir da análise de vídeos de jogadores disponibilizados no portal Youtube, será utilizado o estudo de caso, no qual será analisado o jogo Minecraft, com o intuito de buscar entender aqui os conceitos que serão retratados no decorrer do trabalho. A escolha deste jogo se dá por ser um dos mais requeridos pelas crianças e jovens, possuindo atualmente mais de 74 milhões de jogadores ativos. O jogo Minecraft foi criado por Markus Persson e teve seu lançamento em 2001, desde então vem conquistando mais jogadores. É um jogo que possibilita ao jogador criar seu mundo imaginário através de blocos e assim poder viver nele, enfrentando desafios e aventuras, para garantir sua sobrevivência.

Por fim, nas considerações será retomada a questão central, que instigou a pesquisa, contemplando algumas possíveis respostas para as indagações levantadas no decorrer do trabalho. Desta maneira, reconhece-se que a ludicidade está presente em todos os jogos, que é algo fundamental para a infância e que ambos os jogos, reais ou virtuais, são facilitadores para aquisição de conhecimentos e para o desenvolvimento das crianças. 
O conceito referente ao jogo e à brincadeira ainda não encontrou consenso no âmbito teórico, uma vez que se caracteriza muito em função do contexto histórico e da concepção que os diferentes autores têm a respeito de sua função e lugar social. Assim como, também, é difícil distinguir ou dar um significado específico para o jogo e a brincadeira, uma vez que na maioria das vezes esses termos são usados como sinônimos, embora, ora suas características parecem ser as mesmas em quase todos os jogos, ora se diferenciam.

Evidentemente, pode-se afirmar que a criança aprende e melhor se desenvolve por meio dos jogos e brincadeiras. As atividades lúdicas proporcionam o envolvimento da criança e, portanto, seu desenvolvimento em diferentes aspectos, tais como o cognitivo, motor, linguístico, afetivo, social, entre outros.

Estudos como os de Huizinga (2000), Fortuna (2005), Kishimoto (2011), e tantos outros, têm afirmado que o brincar está intrinsicamente articulado com a cultura, mas também se constitui como uma necessidade humana. Em seu estudo "Homo Ludens", Huizinga (2000) constata que tanto os homens quanto os animais brincam. Neste sentido, à primeira vista, seria possível constatar que o brincar está relacionando a uma dimensão biológica, como uma necessidade que independe do sujeito para se manifestar como um atributo dos seres humanos ou dos animais. Portanto, ele propõe inicialmente que "o jogo é fato mais antigo que a cultura [...] Os animais não esperaram que os homens os iniciassem na atividade lúdica" (HUIZINGA, 2000, p. 05). O autor complementa:

[...] Há uma extraordinária divergência entre as numerosas tentativas de definição da função biológica do jogo. Umas definem as origens e fundamento do jogo em termos de descarga da energia vital superabundante, outras como satisfação de um certo "instinto de imitação", ou ainda simplesmente como uma "necessidade" de distensão. Segundo uma teoria, o jogo constitui uma preparação do jovem para as tarefas sérias que mais tarde a vida dele exigirá, segundo outra, trata-se de um exercício de autocontrole indispensável ao indivíduo. Outras veem o princípio do jogo como um impulso inato para exercer uma certa faculdade, ou como desejo de dominar ou competir [...] (HUIZINGA, 2000, p. 05).

No entanto, em suas análises acaba por trazer à tona uma dimensão antropológica do jogo e do brincar, afirmando que, o que diferencia o brincar dos humanos do brincar dos animais é a produção de sentido, a simbolização e a intencionalidade presentes neste ato. Os sentidos atribuídos ao jogo e os modos como os seres humanos significam e transformam a realidade por meio do brincar comprovam que este assume-se uma dimensão cultural, muito além de uma necessidade biológica. 
$\mathrm{Na}$ busca por compreender a dimensão lúdica do jogo e da brincadeira como constituintes do desenvolvimento infantil, Kishimoto (2011) afirma que sua capacidade de possibilitar experiências de criação e de fantasia, proporcionam caminhos para a aprendizagem. Sendo assim, destaca características de diferentes jogos que contribuem para o desenvolvimento da criança,

Por exemplo, no faz de conta, há forte presença da situação imaginária; no jogo de xadrez, regras padronizadas permitem a movimentação das peças. Brincar na areia, sentir o prazer de fazê-la escorrer pelas mãos, encher e esvaziar copinhos com areia requer a satisfação da manipulação do objeto. Já a construção de um barquinho exige não só a representação mental do objeto a ser construído, mas também a habilidade manual de operacionalizálo (KISHIMOTO, 2011, p.15).

Kishimoto apresenta uma breve contextualização histórica do conceito de jogo. Para ela, primeiramente, o jogo era considerado como uma recreação ou relaxamento, passando posteriormente a ser visto como não sério, pois na época da idade média se fazia relação com os jogos de azar e com aqueles que envolviam dinheiro. Com o passar do tempo, ele se destacou por sua conduta livre que facilitava os estudos e estimulava o desenvolvimento da inteligência, devendo, assim, ser usado como instrumento de ensino, modificando para a forma lúdica alguns conteúdos.

No âmbito da modernidade, o jogo passou a ser compreendido como favorecedor da espontaneidade e liberdade da criança, despertando também o seu imaginário. É possível perceber, no decorrer dos tempos, uma importante influência da biologia, dando ao jogo um caráter limitado ao treino de instintos herdados (KISHIMOTO, 2011). Como as necessidades lúdicas e de brincadeiras eram algo totalmente ignorado, tão logo a criança desenvolvesse a capacidade de se virar sozinha, sem a ajuda de alguém mais velho, já era introduzida ao mundo adulto, exercendo as mesmas atividades, respeitando apenas os limites físicos.

Vale destacar que, assim como o conceito de criança e infância foi se descortinando no âmbito da sociedade moderna, também o jogo e a brincadeira foram sendo percebidos de outras formas, até serem compreendidos como elementos inerentes à vivência da infância. Cada vez mais, a infância passa a ser considerada como uma etapa importante da vida da pessoa, sendo reconhecidas as suas especificidades e as necessidades para o desenvolvimento infantil.

\section{CARACTERÍSTICAS DOS JOGOS E BRINCADEIRAS}


Os jogos e as brincadeiras vêm sendo considerados de suma importância na vida da criança por possibilitarem o desenvolvimento em todas as dimensões. Para Coelho (2011, p. 204), “um dos sentidos do jogo é saciar e preencher nosso desejo interno de sempre continuar brincando, enfrentando desafios e principalmente o desejo maior de vencer". Para o autor, o jogo é uma atividade livre, voluntária, que dá prazer e envolve o jogador. Ao jogar, o ser humano pode ao mesmo tempo relaxar e se desligar por alguns instantes do mundo real e tornar-se pertencente apenas do seu mundo imaginário, sendo um personagem do seu próprio jogo. É também considerado uma atividade temporária, ou seja, regido por um limite de tempo. O jogo pode, também, sofrer uma limitação de espaço. Segundo Pianovski(2012)

[...] O jogo é exercido dentro de um espaço e tempo delimitado, e consiste na representação de alguma coisa ou na luta pela conquista de algo. $\mathrm{Na}$ representação de algo o homem assume um papel, muitas vezes tornandose outra pessoa (PIANOVSKI, 2012, p. 50).

No entanto, essas características podem ocorrer em brincadeiras livres, nas quais se elegem os lugares em que a brincadeira ocorrerá. Da mesma forma, a noção de tempo não é fixa, mas temporária, pois a brincadeira vai durar até se ter o envolvimento completo dos integrantes, logo após essa brincadeira termina e se inicia outra. Já nos jogos sérios e de competição, o espaço e o tempo são bem definidos, como, por exemplo, em um jogo de futebol, que deve acontecer em um campo cujo tamanho é designado pelas linhas, tendo também um limite de tempo para se realizar. Acabando esse tempo, o jogo é encerrado e se tem o time vencedor, perdedor ou ainda há a possibilidade do empate.

Como citado nesse exemplo anterior, o tempo e o espaço são considerados como uma das regras existentes para o jogo. Sendo assim, essa é outra característica importante, pois são as regras que definem o jogo e o estruturam para se ter um bom entendimento e sua plena execução. O não cumprimento de uma dessas características acarreta na eliminação e/ou fim de jogo.

Isso também faz com que o jogo tenha uma ligação com o estético, o belo e perfeito. A desobediência no momento em que se está jogando, o estraga: "o jogador que desobedece às regras é chamado de 'desmancha-prazeres', pois destrói o mundo mágico e esta figura é mais nítida nas brincadeiras infantis" (BERNARDES, 2005, p. 46), pois pode acabar por provocar conflitos, desentendimentos, punição e até cancelamento do mesmo. Tais regras, que podem estar explícitas ou não, dão sentido ao jogo e ao mesmo tempo os distinguem dos demais. Para Huizinga (2000), 
Por sua vez, estas regras são um fator muito importante para o conceito de jogo. Todo jogo tem suas regras. São estas que determinam aquilo que "vale" dentro do mundo temporário por ele circunscrito. As regras de todos os jogos são absolutas e não permitem discussão [...] (HUIZINGA, 2000, p.12).

É no entendimento das regras que as crianças aprendem a ter limites, a saber, esperar, a ter noção de tempo e espaço, desenvolvendo seu raciocínio lógico, cognitivo e motor.

Outra questão que também ajuda em seu desenvolvimento é o fato do jogo demandar construção e execução das regras. Exceto nas brincadeiras que já possui suas regras pré-estabelecidas, como, por exemplo, a amarelinha ou o pega-pega, apenas no jogo pode-se criar ou adaptar novas regras. Ao construí-las, a criança está desenvolvendo seu intelectual, já que precisa pensar e elaborar circunstâncias coerentes com o ambiente jogado. Desenvolve-se, também, a comunicação e as competências sociais, por meio das trocas e negociações na preparação do jogo, em como irão jogar e como será a distribuição dos papéis, uma vez que, em uma brincadeira de polícia e ladrão, por exemplo, as crianças precisam juntas decidir quem será a polícia, quem serão os ladrões e como se dará o andamento da mesma.

Nesse momento, também, as crianças podem se tornar as mediadoras do jogo, ditando as regras. Elas avaliam a execução do jogo e o respeito a suas regras, corrigindo caso necessário. Com base nessa discussão, Kishimoto apresenta a importância dessas regras,

A existência de regras em todos os jogos é uma característica marcante. Há regras explicitas como no xadrez ou na amarelinha, bem como regras implícitas, como na brincadeira de faz de conta, em que a menina se faz passar pela mãe que cuida de sua filha. Nessa atividade são regras internas, ocultas, que ordenam e conduzem a brincadeira (KISHIMOTO, 2016, p. 4).

Em outra dimensão, nas brincadeiras ou nos jogos de faz de conta, a criança estará representando papéis, que podem ser inventados ou reproduzidos de acordo com alguma situação que ela vivenciou e a marcou positivamente ou não.

Nas brincadeiras de faz de conta pode-se observar, por meio do comportamento da criança, alguma ação ou situação vivida por ela. Por exemplo, quando a criança se coloca no papel de professor, ao tratar seus alunos imaginários com aspereza, gritos e punição, tem-se a possibilidade que esta situação esteja ocorrendo na realidade, com ela ou com seus colegas. Essa situação é notada para qualquer ambiente que ela frequenta, pois em vários momentos a criança reproduz o que vê e o que vivenciou: 
É através do faz-de-conta que a criança tem a possibilidade de experimentar diferentes papéis sociais que conhece e vivencia no cotidiano de suas histórias de vida [...]. Através do faz-de-conta a criança pode, também, reviver situações que lhe causam excitação, alegria, medo, tristeza, raiva ou ansiedade. Elas podem nesse jogo mágico, expressar e trabalhar as fortes emoções muitas vezes difíceis de suportar. É a partir de suas ações nas brincadeiras que elas exploram as diferentes representações que tem destas situações difíceis. Assim, podem melhor compreendê-las e reorganizá-la (DORNELLES, 2001, p. 105-106).

A representação de papéis também é vista como um treinamento para a vida adulta. Um exemplo disso é quando a menina está brincando de boneca ou de casinha, pois está na verdade representando o papel da mãe que cuida da sua casa e que cuida de seus filhos. Muitas vezes, ela presencia situações em sua casa com sua mãe, e em algum momento vai entender isso como algo que será presente em seu futuro. Nesse sentido, é preciso romper com uma construção social estereotipada a partir dos gêneros, que contribui para a reprodução dos modelos tradicionais de feminino e masculino.

A brincadeira de faz de conta não se limita apenas à representação de papéis. Ela também está ligada ao mundo imaginário e ao sonho, em que a criança se torna um objeto qualquer e a partir da sua escolha começa a reagir conforme as características do mesmo. Assim, sem ter ligação nenhuma com o seu cotidiano, ela inventa-se como um astronauta, um herói ou um personagem dos contos de fadas, já que, de alguma forma, um desses elementos chamaram a sua atenção, fazendo com que se inspire a imitar. "[...] Nessa forma, a criança finge ser outra pessoa ou um objeto, imitando, com o seu próprio corpo, as características do ser ou objeto imaginado, como uma fada ou super- - herói” (HORN, 2012, p. 68).

Seu imaginário proporciona não só a imitação de um objeto com o seu próprio corpo, mas também, atribui a um determinado objeto a função do outro. Quando a criança, por exemplo, pega uma tampa de panela e diz ser um volante de carro, ou quando pega uma caixinha de fósforo e finge ser um carrinho, ele está, em seu imaginário naquele momento, brincando e agindo conforme são as características desse objeto, fazendo seus sons e comportamentos. Dornelles (2001) discute que brincando a criança cria e recria o seu mundo,

[...] A brincadeira é algo que pertence à criança, à infância, através do brincar a criança experimenta, organiza-se, regula-se, constrói suas normas para si e para o outro. Ela cria e recria a cada nova brincadeira o mundo que a cerca. O brincar é uma forma de linguagem que a criança usa para compreender e interagir consigo, com o outro, com o mundo (DORNELLES, 2001, p.104). 
No mundo imaginário que a criança constrói tudo pode acontecer e quem dita as regras é ela mesma. É a própria criança que tem a autonomia de fazer suas escolhas e decidir como quer jogar. Essa iniciativa favorece o seu convívio e desenvolvimento social, uma vez que em um jogo livre ou em um jogo com um grupo maior de crianças, a comunicação deverá prevalecer durante as escolhas das regras desse tal jogo, de maneira que todos fiquem satisfeitos com os seus papéis. Segundo Bernardes (2005),

Brincando e jogando, a criança estabelece vínculos sociais, ajustando-se ao grupo e aceita a participação de outras crianças com os mesmos direitos. Obedece às regras traçadas pelo grupo, como também propõe suas modificações. Aprende a ganhar, mas também a perder [...] (BERNARDES, 2005, p. 52).

Outro fator em comum é a utilização de determinadas peças (objetos) específicos que fazem parte do jogo. Segundo Kishimoto (2011), um mesmo jogo pode ter sentido diferente dependendo da linguagem de cada cultura, do significado que cada sociedade emprega. Um exemplo disso é o arco e flecha, que antes era visto como um preparo profissional e hoje como um mero brinquedo. "Dessa forma, enquanto fato social, o jogo assume a imagem, o sentido que cada sociedade lhe atribui." (Kishimoto, 2011, p. 19).

O brincar e o jogar favorecem, também, a construção da personalidade da criança, assim como o desenvolvimento do juízo de valor e da moral. Isso ocorre pelo fato das construções das regras e do seu comprimento, pois nesse momento a criança precisa pensar e respeitar a outra, já que no jogo coletivo todos têm o mesmo direito de opinião e decisão, assim como sua vez para jogar, ou seja,"[...] Por meio do brincar, a criança vai compondo uma infinita abertura de possibilidades que the permitirão desenvolver-se integralmente como sujeito engajado no processo de construção de si mesmo" (Horn, 2012, p. 91).

É possível, também, detectar sua desenvoltura e comportamento nos momentos de brincadeiras e jogos, percebendo se a criança é quieta ou falante, se é tímida ou extrovertida, como se apresenta quando é contrariada, se é esperta ou distraída, e assim por diante. É esse um marco rico na vida da criança para seu desenvolvimento, além do conhecimento e entendimento para com a criança a partir da observação destes momentos lúdicos, que acontecerá se for permitido à criança, um brincar livre, na qual ela mesma toma suas decisões, enfrenta as dificuldades/conflitos e aprende a lidar com as situações que vão surgindo ao longo do jogo, sem que um adulto ou outra criança interfira nas escolhas. Horn (2012) afirma que, 
O brincar, na infância, favorece a construção de sua personalidade. Se o desejo for educar crianças autônomas capazes de organizar brincadeiras criativas e espontâneas [...] Deve-se ter presente a ideia de que o brincar é construtor de novas aprendizagens e de interações muito significativas, principalmente na infância, uma etapa tão importante de seu desenvolvimento (HORN, 2012, p. 11).

Segundo Friedmann (1998), as brincadeiras são transmitidas de geração a geração, mudando algumas vezes a sua forma e suas regras, dependendo da cultura que está inserida. Vistas como patrimônio lúdico-cultural é responsável por traduzir costumes, valores e ensinamentos.

O brincar para a criança deve acontecer de modo voluntário, de modo que a mesma sinta prazer de estar brincando, pois é assim que a criança estará expressando seus sentimentos, suas emoções, suas alegrias e angústias. Além de, também, ser um ótimo momento para a criança aprender. Sendo assim, o brincar é um direito que toda e qualquer criança deve ter, como afirma Kishimoto (2011),

Entre as coisas de que a criança gosta está o brincar, que é um de seus direitos. O brincar é uma ação livre, que surge a qualquer hora, iniciada e conduzida pela criança; dá prazer, não exige como condição um produto final; relaxa envolve, ensina regras, linguagens, desenvolve habilidades e introduz a criança no mundo imaginário (KISHIMOTO, 2011, p. 1).

Diante disso, dessas características presentes nos jogos, que foram citadas anteriormente, abordaremos na próxima seção as característica do jogo na comparação entre suas dimensões real e virtual.

\section{CARACTERÍSTICAS DO JOGO VIRTUAL E SUA COMPARAÇÃO COM O JOGO REAL}

Como visto na seção anterior, os jogos e as brincadeiras se limitavam a uma atividade livre, voluntária e dinâmica, que acontecia em determinados espaços e muitas delas eram temporizadas e regradas. Em outras palavras, o jogo acontecia exclusivamente no mundo real. Mesmo havendo a contribuição da imaginação na hora de jogar, a sua concretização se dava no real, na manipulação de objetos e brinquedos e no envolvimento com o outro.

Há mais de meio século, essas características vêm se modificando e a restrição do real se torna optativa para as crianças, uma vez que desde muito cedo elas já estão inseridas nesse contexto virtual. Assim, "o intrigante, e talvez o maior motivo de sucesso e atração do game, é a sua mistura de jogo e realidade. Afinal, são pessoas reais, convivendo sob regras lúdicas" (ABREU, 2003 p .07). 
Dentre as características que são evidenciadas nos jogos eletrônicos, o movimento corporal nem sempre está presente, a não ser em jogos próprios da última geração dos consoles, que permitem movimentos graças a tecnologias de reconhecimento de gestos, como o caso do Nintendo Wii e do Kinect do $X$ Box. Diferentemente do jogo real, como já mencionado, que tem o envolvimento com alguns objetos e brinquedos, no jogo virtual esse envolvimento acontece através da manipulação de um joystick no apertar de seus botões, sendo esse o único manejo da criança para fazer com que o jogo aconteça. Essa ferramenta proporciona a criança, criar, interpretar e decidir sobre situações que vão aparecendo no decorrer do jogo. Tudo isso, perante as regras que são delimitadas pelo jogo. Todo jogo tem um objetivo a alcançar e, assim, o jogador precisa enfrentar os desafios, com base nas regras que lhe são impostas, avaliando as situações e criando suas estratégias para vencer. "Os videogames lançam inúmeros desafios ao jogador, que se vê obrigado a tomar uma série de decisões de curto e longo prazo, baseados na avaliação constante das informações disponíveis." (CALDAS, 2007, p.06).

Outra característica importante do jogo eletrônico é a dimensão da oportunidade da imaginação. Seus cenários são bem elaborados e bonitos, permitindo assim que o jogador se envolva prazerosamente no jogo. Quando se trata das crianças, esse é um ponto fundamental que chama atenção e garante seu envolvimento pleno. Tal componente facilita a imaginação e a fantasia da criança em fazer parte daquele mundo. Em outras palavras, em se colocar no papel dos personagens do jogo, além é claro, de permitir ser a detentora do poder, comandar a situação, conduzindo o jogo à sua maneira. Assim, para Munguba (2003),

A fantasia é bastante estimulada através da realidade virtual pelo videogame. Tanto é assim que se ouvem depoimentos de crianças durante o jogo, como: "eu morri duas vezes, mas consegui matar o meu inimigo", ou "eu vou subir e fugir do meu inimigo", sempre se referindo à personagem como sendo ela própria (MUNGUBA et al, 2003, p. 42).

Em contrapartida ao jogo real que, na maioria dos jogos, decorrem do envolvimento com o outro e com o ambiente que se está jogando, a interação não ocorre nos jogos virtuais, ainda que haja a possibilidade de se jogar o videogame com mais pessoas, cada uma manejando seu joystick. Porém, atualmente, não se vê muito essa prática, uma vez que o jogador sozinho basta para fazer com que o jogo aconteça e seu espaço se limita à frente de uma tela ou visor de televisão, computador ou celular.

Porém, não há algum tempo atrás, surgiram também os jogos online, que por meio da internet, proporcionam em um pequeno tempo um envolvimento na hora do jogo com 
outro jogador de qualquer lugar do mundo. Embora esse envolvimento aconteça, limita-se apenas a jogar com o outro, ou com um grupo maior, mas as trocas ou processos de socialização entre eles ficam nulos ou restritos aos chats do jogo.

Sendo essa uma interação virtual, ocorre também uma preocupação no sentindo dessa interação ser com desconhecidos, já que as pessoas que ali estão jogando nunca se viram ou conversaram antes, apenas estão em contato durante o jogo. Isso acarreta certo perigo se a criança acabar, em sua ingenuidade, se envolvendo mais a fundo com outro jogador, estar suscetível a inúmeras situações, como passar informações confidenciais, expor sua imagem, entre outros, colocando em risco assim sua privacidade e segurança.

Por outro lado, o jogo virtual pode também estar diretamente ligado ao desenvolvimento da criança, pois "Uma das principais funções da brincadeira é o desenvolvimento das relações entre a criança e o mundo, desta forma os aparelhos eletrônicos nos colocam diante de novas formas de aprender brincando" (CALDAS, 2007, p. 01). Desde que o seu uso seja de maneira consciente e com a supervisão de um adulto, na hora de escolher o jogo adequado à faixa etária, pois caso isso não aconteça tem-se a reversão do sentido do jogo e de sua contribuição para o desenvolvimento infantil.

Essa reversão acontece se o jogo for usado como uma forma de passatempo, para entreter a criança, sem um propósito educativo. Muito se ouve falar que para que os adultos possam realizar suas atividades corriqueiras, não podendo assim dar a atenção aos seus filhos (as), por excesso de trabalho ou compromissos, por exemplo, acabam tendo a ideia de suprir essa ausência por meio dos jogos virtuais, deixando que seus filhos joguem à vontade e em qualquer horário e lugar. Essa realidade está cada vez mais presente entre as crianças que ficam a maioria do tempo em frente ao computador, televisão e celular, jogando.

Não sendo o único ponto negativo essa prática sem intencionalidade, há também o fato do jogo virtual se tornar vicioso, quando jogado consecutivamente. Ou seja, "a áurea má dos jogos é um tanto óbvia. Como tudo o que gera prazer no homem, o jogo também pode se tornar uma compulsão, trazendo prejuízos pessoais ao dependente" (ABREU, 2003 p. 2). Dessa forma, a criança ao jogar se encanta e quer sempre jogar mais, ficando muito tempo ligado àquilo e se desliga do mundo real, não se envolvendo fisicamente com outras pessoas e nem se movimentando para outros ambientes. Ao ficar presa somente a essa atividade de jogar, a criança estará prejudicando sua saúde física e comprometendo sua saúde mental, deixando de realizar suas atividades com a mesma facilidade de antes. Isso porque segundo D'Ancora (2012), o desenvolvimento motor está ligado ao ambiente, e ao 
estímulo que a criança tem nessa fase. Se estiver apenas em contato com os jogos virtuais e não estiver vivenciando atividades de movimentos consecutivamente, pode ter seu potencial limitado. Entende-se que "[...] cada criança apresenta seu padrão característico de desenvolvimento, visto que as características inerentes sofrem a influência constante de uma cadeia de transações que se passam entre ela e o ambiente que a circunda" (D'ANCORA, 2012, S/P).

No entanto, utilizado de maneira correta e saudável o jogo virtual tem muito para contribuir no desenvolvimento das crianças, assim como o jogo real. Segundo Caldas, alguns pesquisadores afirmam que os games estimulam e melhoram a memória do jogador, pois em quase todos os jogos é necessário o uso de hipóteses, truques e estratégias para conseguir avançar de fase, usando assim da iniciativa e do raciocínio lógico para realizar as tarefas solicitadas.

Criando situações, a criança acaba por desenvolver sua criatividade, explorando todas as maneiras e possibilidades de jogar e fazer com que as ações aconteçam. Nessa iniciativa de tomar decisões, por exemplo, a criança desenvolve também a sua autonomia, pois é ela própria que precisa criar suas soluções, decidir o que fazer e aceitar as consequências que suas escolhas irão ter, e que podem ser as certas ou não, facilitando ou complicando mais o jogo, tendo que decidir assim outras mais escolhas.

Outro fator importante para se considerar é de que os jogos virtuais educativos, voltados especificamente para o aprimoramento de alguns conteúdos e conceitos, são grandes aliados à educação, pois proporciona de forma lúdica o entendimento dos conteúdos de várias áreas do conhecimento. Dessa forma, escolas e professores, tendo o entendimento dessa gama de jogos e dos benefícios para o desenvolvimento da criança, podem utilizar-se dessa ferramenta como uma estratégia e fazer parte da sua metodologia de ensino.

Há jogos que já são pensados e criados, com a intenção educativa, porém há outros que acabam por ter esses elementos apenas como componentes, tornando-se assim, sem querer, um jogo educativo:

Muitos games são projetados sem a pretensão de pertencer ao gênero educativo. Contudo, quando um jogo eletrônico possui elementos como lógica, matemática e exercícios visuais que estimulam o raciocínio e o exercício da atividade cerebral, ele acaba se tornando um jogo educativo por acidente (BARBOZA e SILVA, 2014, p. 9).

Pensando sobre as contribuições que o jogo possibilita e, dentre eles, os jogos mais jogados pelas crianças, é possível destacar, no campo virtual, o Minecraft. Assim, optamos 
por analisar esse jogo no próximo capítulo com maior precisão. Sendo esse jogo usado como objeto de estudo, sua escolha se deu pelo fato de ser um dos jogos mais procurados pelo público infantil e por ser um jogo diferente dos outros, tendo como características específicas a criatividade e a ludicidade como seu grande triunfo.

\section{O JOGO MINECRAFT, SUAS PRINCIPAIS CARACTERÍSTICASE A LUDICIDADE}

Sendo especificamente do campo virtual, o Minecraft é um jogo no estilo sandbox, em que o jogador tem a liberdade de seguir e tomar as decisões que quiser: "O Minecraft segue o estilo sandbox (caixa de areia), de mundo aberto, cheio de possibilidades, permitindo que o jogador possa seguir o caminho que quiser e tomar suas próprias decisões sobre o que fazer" (SOUZA e CANIELLO, 2015, p. 40).

Desse modo, esse jogo, assim como todos os outros, possui algumas regras e delimitações para seu andamento, porém não existe uma forma específica de se vencer. Seu objetivo é coletar materiais, conseguir sobreviver aos desafios encontrados e fazer construções.

Outra característica do Minecraft é que possui um Avatar. Em outras palavras, o protagonista principal. O nome desse Avatar é Steve, ele representa todas as ações do jogo, conforme as decisões tomadas pelo jogador, ou seja, com ele o jogador realiza as construções de sua preferência. Esse Avatar pode também ser modificado, conforme a preferência do jogador, assim como os cenários, monstros e animais podem ser personalizados. Popularmente conhecido como lego virtual, pelo fato de ser voltado para a construção de objetos e paisagens conforme a imaginação do jogador, o Minecrafté um jogo em que o cenário montado é completamente formado por blocos minerados. "Assim, o "Minecraft é um jogo eletrônico que permite a construção usando blocos (cubos) dos quais o mundo é feito, onde os jogadores ficam minerando e construindo blocos de material virtual, de onde derivou o nome do jogo" (CORREA, 2015, p. 04). Essas características são ressaltadas também por Souza (2018):

[...] Todos os objetos que compõe o jogo, como sujeira, pedra, minérios, troncos de árvores, água e lava são representados por meio dos blocos e as ações e decisões do jogador giram em torno de quebrar e colocar esses objetos, organizá-los em uma grade 3D, enquanto os jogadores podem se mover livremente ao redor do mundo. Os jogadores podem minerar blocos e depois colocá-los em outro lugar, o que permite a construção de objetos, prédios etc. (SOUZA, 2018, p. 44).

Essa característica permite ativar a criatividade e o imaginário dos jogadores, pois são variados os formatos e objetos construídos e de diversos tipos: de casas (de campo, 
casa simples, de luxo, casa na árvore, etc), de prédios, de castelos (pequenos, grandes, medievais, etc), cidades, etc. Como também, permite a criação de animais, de flores, paisagens, entre outros.

As construções feitas em Minecraft permitem ao jogador criar um mundo próprio, com base na sua criatividade, vontade e desejo, pois o jogador, nesse processo, pensa em todas as características e detalhes para melhor realizar a sua construção. Todas essas ações ocorrem em um mundo próprio, denominado de mapa, que é o espaço que o jogador tem para explorar. Essas ações podem ocorrer durante o dia e a noite, sendo este outro aspecto relevante do jogo, pois há ações que são propícias para o dia, como comer, minerar, construir, e outras que ocorrem à noite, como se proteger dos monstros (zumbi, esqueleto, aranha) existentes, chamados demobs.

Outra característica importante de se considerar é que, dentro do próprio jogo, o jogador pode recriar novos jogos, através dos chamados modificadores (mods):

Outras particularidades verificadas no jogo Minecraft dizem respeito aos modos de jogo e a variabilidade do seu sistema de dificuldade. O jogador pode optar dentre quatro maneiras de jogo: sobrevivência, criatividade, aventura e espectador. Também possui um sistema de dificuldade variável de cinco níveis (SOUZA, 2018, p. 47).

É nítido que essas características presentes nesse jogo, contribuem para desenvolvimento de seu público alvo, pois permite desenvolver sua autonomia, tomada de decisões, aguçar a criatividade entre outros, bem como, possuem uma proximidade com os jogos reais que também envolvem a criatividade, ludicidade, tomada de decisões, entre outros elementos propícios para o desenvolver da criança.

O jogo Minecraft chama atenção por ser um jogo com cenário próprio e designer bem elaborado, bonito, colorido e agradável. No entanto, do ponto de vista gráfico, não é nada sofisticado ou inovador e, ao contrário de seus grandes concorrentes, não tem nenhum aparato do realismo, já que tudo no jogo é formado e se consiste por blocos. Mas, mesmo assim, ele atrai de forma significativa seu público.

Seu grande triunfo é o despertar da imaginação, da criatividade que faz com que o jogador se interesse. Suas características atraem principalmente as crianças, que são atualmente o público alvo desse jogo, pois permite que elas façam várias criações, tenha seu próprio mundo, expanda outros novos, enfrente desafios e monstros.

Diante disso, este jogo, assim como qualquer outro, possui sua limitação de espaço, como uma de suas características presentes, ou seja, "todo jogo se processa e existe no 
interior de um campo previamente delimitado, de maneira material ou imaginária, deliberada ou espontânea" (HUIZINGA, 2000, p. 11).

Porém, esse recinto é delimitado no sentido de que o jogador tem seu espaço, denominado mapa, que poderá explorar da maneira que quiser, conseguindo também, na medida em que o jogo avançar, conquistar outros espaços/mapas. Mas, diferentemente de outros jogos virtuais que primam para a realidade virtual, o Minecraft aposta no lúdico, que para Souza e Caniello (2015) "o lúdico é o lugar no qual as forças da razão e da sensibilidade se fazem presentes e, por ser um componente fundamental em um jogo, é o maior responsável pelo potencial de desenvolvimento de habilidades sócio afetivas e cognitivas" (SOUZA E CANIELLO, 2015, p. 39).

Sendo assim, consequentemente, o game contempla algumas dimensões, como a do mundo livre, a do resgate de brincadeiras tradicionais e da possibilidade da socialização. Essas dimensões estão completamente ligadas ao campo da imaginação. O jogo Minecraft é um jogo open-world, ou seja, é um jogo de mundo livre, não tem restrições espaciais, nem regras e fases determinadas, sendo diferente da maioria dos outros games, dos quais precisam seguir fases, ou desafios propostos para dar continuidade no jogo e vencer. Assim, cabe ao jogador criar o que fazer, suas próprias regras, com próprios mecanismos, jogos simbólicos e trocas sociais de convencimento, de papéis, do que cada um vai fazer:

[...] os jogadores codesenham os jogos pelas ações que executam e as decisões que tomam. Os jogadores de Minecraft são cocriadores do universo do jogo e capazes de modificá-los, livremente, procurando novas significações que fazem com que o game não se torne monótono e exaustivo (SOUZA e CANIELLO, 2015, p. 42).

No Minecraft é muito comum, também, usar do espaço virtual para o resgate de jogos/brincadeiras tradicionais como pega-pega, esconde-esconde, polícia-ladrão, entre outras. Algo que não é possível realizar em outros jogos virtuais, pois cada jogo tem sua temática, seu objetivo. Por exemplo, se em outro jogo virtual, o jogador estiver jogando futebol, não tem como brincar de amarelinha. Diferente do Minecraft, que o jogador constrói, enfrenta monstros, minera, etc., e pode também, em seu mundo, brincar de diferentes tipos de brincadeiras.

Dado isso, outra coisa que vem como consequência é a possibilidade de socialização que, por mais que se possa jogar sozinho, o grande prazer é poder jogar em grupo, com os amigos, permitindo assim a interação, a qual: "[...] se dá no contexto da relação dialógica entre os jogadores, que compartilham experiências nas comunidades, fóruns virtuais e dentro do próprio jogo [...]" (SOUZA e CANIELLO, 2015, p. 42). Ainda segundo os autores, 
o Minecraft não foi criado com fins educativos, mas mesmo assim ele contribui na medida em que se joga com requisitos de aprendizagem, como afirma Knittel (2017),

Durante o jogo, é possível estudar conceitos matemáticos, físicos, arquitetônicos, geográficos e de outras disciplinas que envolvem volume, área, gravidade, relação entre substâncias, probabilidade, entre outras disciplinas e conteúdos. Apesar de não ter sido criado para fins educacionais, muitos educadores enxergaram no jogo a possibilidade de ensinar diversas matérias a partir da ludicidade da construção. (KNITTEL, 2017, p.791).

Com base nessas dimensões, é notório ver o quanto o jogo Minecraft tem atributos para chamar a atenção e encantar seus jogadores. Com ele é possível representar papéis, construir objetos e mundos, ter autonomia de fazer suas escolhas e resolver conflitos. De forma significativa esse jogo está ligado ao desenvolvimento e aquisição de conhecimentos e potencialidades, tendo a imaginação e o lúdico ligados de forma a contribuir nesse processo.

Vale ressaltar que o jogo tem uma importância fundamental para a criança, desde que seja também utilizado de forma equilibrada e intercalada com os jogos reais, não se tornando o único protagonista de suas vidas. Para a criança é fundamental sua interação com o ambiente, com a realidade e com pessoas.

\section{CONSIDERAÇÕES FINAIS}

Vivemos na era digital, tempo em que a tecnologia está tomando conta de diferentes áreas no mundo. Objetos, serviços e instrumentos de comunicação que anos atrás jamais imaginaríamos existir, hoje estão presentes por toda parte e para todos os públicos. Este é o caso dos jogos virtuais, que foram o objeto de estudo para este trabalho. Este artigo apresentou como questão inicial: o que há de lúdico no jogo virtual e quais permanências e diferenças ele apresenta em relação ao jogo real? Para responder esta questão, foi feito uso do estudo de caso para proceder com a análise do jogo Minecraft.

Os objetivos deste estudo foram, portanto, analisar o conceito de jogo e suas características, investigar quando surgiram os jogos virtuais e sua evolução, compreender o porquê de o jogo virtual chamar tanta atenção de seu público e entender de que maneira os jogos estão envolvidos como favorecedores do desenvolvimento infantil. Foi possível, no decorrer dessa pesquisa, apresentar os vários conceitos expressos a partir do referencial teórico, que se tornaram capaz de responder, tanto a pergunta inicial como conseguir, também, analisar os objetivos propostos. 
Diante do exposto, um dos aspectos constatados é que o jogo vem antes que a cultura, como uma necessidade instintiva, pois os animais já apresentavam atividades lúdicas em suas ações. No entanto, é na cultura que ele se expressa e se constitui como uma criação do homem. Assim, tanto os jogos virtuais como os jogos reais são importantes no desenvolvimento das crianças. Ainda que cada um, em comparação com o outro, possua suas especificidades e características, ambos possuem semelhanças.

Dentre as semelhanças, por exemplo, existem algumas regras universais que, de acordo com Barboza e Silva (2014), existem e são conservadas porque na maioria das vezes são acompanhadas pelos seus jogadores, que independente do lugar que estejam mantém suas regras originais, ainda que com adaptações oriundas de contextos locais específicos. Além dessas semelhanças, é possível notar a presença de regras explícitas como limitação de tempo e espaço, objetivos e desafios a cumprir, bem como a imaginação, criatividade e, principalmente, a ludicidade, presente entre os jogos e que é de fundamental importância para o desenvolvimento da criança.

Muitas vezes os jogos virtuais são estigmatizados pelos casos nos quais a relação entre o jogo e o jogador se torna compulsiva, dando origem ao comportamento vicioso. Nesse sentido, compreendemos que a família e os professores são sujeitos que podem e devem prover uma consciência progressiva para a autonomia, salientando junto ao público infanto-juvenil a importância da temática dos jogos, das indicações de classificação etária e do tempo direcionado para a atividade. A mediação nos jogos virtuais se faz necessária para que sejam usados de maneira adequada e para que se tornem um instrumento que facilite seu desenvolvimento, para não ter um resultado contrário e prejudicial a sua saúde, tanto no aspecto físico como mental. Visto que a tecnologia, de modo geral, veio para facilitar a vida das pessoas e proporcionar prazer e diversão, os jogos eletrônicos, por sua vez, não precisam ser vistos como vilões, pois eles, apesar de terem seus riscos, têm muito a contribuir na formação e desenvolvimento da criança, basta saber a maneira adequada de usá-lo. Dessa forma, o prazer, a diversão e a ludicidade, elementos chaves da experiência na infância, estarão presentes em todos os jogos, tanto nos reais como aos os virtuais. Mesmo aqueles jogos virtuais que, na maioria dos casos, não são criados para fins educativos, podem ser usados para essa finalidade pois, consequentemente, os jogos possuem a capacidade intrínseca de aguçar o desenvolvimento motor, cognitivo, intelectual e afetivo.

Para concluir, com base no que foi exposto neste trabalho, com a análise específica do jogo virtual denominado de Minecraft, é possível constar que se permeiam dimensões 
lúdicas muito próximas às presentes nos jogos reais conduzidos pelas ações livres, com possibilidades de escolhas e tomadas de decisão. Na contramão da geração de games lançados no mercado em sua geração, Minecraft não apresenta investimento na aproximação da experiência com o mundo real, técnica conhecida como realidade virtual. Seu visual simples e esteticamente grosseiro causa, a princípio, um estranhamento que, sobretudo quando observado seu sucesso ante o público infantil, nos move a entender qual o segredo para o êxito do jogo. Nas análises dos vídeos pudemos observar que as características do game propiciam a experimentação de aspectos da ludicidade por meio do jogo virtual: a liberdade de criar o roteiro, os objetos e sentidos da experiência de jogar Minecraft. Não à toa, o jogo propicia o resgate de algumas das brincadeiras tradicionais, despertando a imaginação de seus jogadores, bem como a possibilidade de socialização, sendo possível ter constante interação com os outros jogadores.

Dessa maneira, concluímos que os jogos virtuais e, em especial, o Minecraft, podem oferecer estruturas que possibilitem uma interação lúdica entre os sujeitos, experiência que será somada às competências midiáticas que são demandadas ao jogador. Todavia, ainda que apresente possibilidades de ludicidade, o jogo virtual enfrenta dificuldades em suprir completamente as experiências que decorrem dos jogos e brincadeiras do mundo real, sobretudo nas relações entre os sujeitos, na construção das narrativas e no uso do corpo. Mas, todavia, os jogos virtuais consumidos pela infância podem ser fator agregador que, usado em medidas adequadas, e somados às brincadeiras e jogos do mundo real, propiciem o desenvolvimento integral da infância.

\section{REFERÊNCIAS}

ABREU, A. VIDEOGAME:UM BEM OU UM MAL? Um breve panorama da influência dos jogos eletrônicos na cultura individual e coletiva. São Paulo, 2003.

BARANITA, I. M. C. A importância do Jogo no desenvolvimento da Criança. Lisboa, 2012.

BARBOZA, E. F. U.; SILVA, A. C. A. A evolução tecnológica dos jogos eletrônicos: do videogame para o newsgame. 5o Simpósio Internacional de Ciberjornalismo. Campo

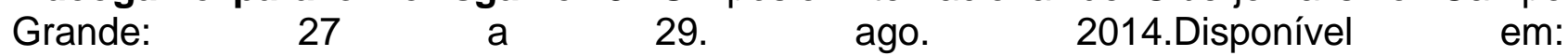
<http://www.ciberjor.ufms.br/ciberjor5/files/2014/07/eduardo.pdf>Acesso em: 24 ago. 2018.

BERNARDES, E. L. Brincadeiras: ontem e hoje. Cadernos de História da Educação. n. 4, jan./dez. 2005. 
CALDAS, R. O. P. O jogo e o desenvolvimento da criança: do consumo à criatividade. $2007 . \quad$ Disponível em: <http://www.pucrio.br/pibic/relatorio_resumo2006/relatorio/CTCH/Psi/Renata\%20de\%200liveira\%20Pinto \%20Caldas.pdf> Acesso em: 24 ago. 2018.

COELHO, P. M. F. Um mapeamento do conceito de jogo. Revista Geminis. São Paulo, 2011. n. 1, p. 293-311.

D'ANCORA, M. H. S. C.A importância do desenvolvimento motor infantil. 2012. Disponível em: <https://institutopensi.org.br/blog-saude-infantil/a-importancia-dodesenvolvimento-motor-infantil/> Acesso em: 30 ago. 2018.

DORNELLES, L. V. Na Escola Infantil todo Mundo Brinca se Você Brinca. In: CRAIDY, C.; KAERCHER, G. E (Org). Educação Infantil Prá que te quero? Porto Alegre: Artmed, 2001. cap. 9. p. 101-108.

FRIEDMANN, A. A evolução do brincar. In: FRIEDMANN, A.; et al. O direito de brincar: a brinquedoteca. 4. ed. São Paulo: Edições Sociais: Abrinq, 1998. p. 25-35.

HORN, C. I.; et al. Pedagogia do brincar. Porto Alegre: Mediação, 2012. cap. 1. p. 13-44.

HUIZINGA, J. Homo Ludens: o jogo como elemento da cultura. 4. ed. São Paulo: Perspectiva, 2000.

KNITTEL, T.; et al. MINECRAFT: Experiências de sucesso dentro e fora da sala de aula. XVI SB Games: Curitiba, 2017. Disponível em: < https://www.sbgames.org/sbgames2017/papers/CulturaFull/175083.pdf> Acesso em: 30 set. 2018.

KISHIMOTO, T. M. O jogo e a educação infantil. São Paulo: Cengage Learning, 2016. 72 p.

KISHIMOTO, T. M. (Org.). Jogo, brinquedo, brincadeira e a educação. 14. ed. São Paulo: Cortez, 2011.

MUNGUBA, M. C. S. et al. Jogos eletrônicos: apreensão de estratégias de aprendizagem. RBPS: 2003, p. 39-48.

NEVES, I. História e Jogos Digitais. 2010. Disponível em: <http://historiaejogosdigitais.blogspot.com.br/2010/05/evolucao-dos-jogos.html> Acesso em: 22 ago. 2018.

PIANOVSKI, R. B. O jogo como mediação da aprendizagem dos alunos de escola multisseriada. 2012, 166 f. Dissertação (Mestrado em Educação) - Universidade Tuiuti do Paraná, Curitiba, 2012.

PIMENTA, J. G. A importância dos jogos e brincadeiras na Educação Infantil. 2011, 41 f. Monografia (Pós-graduação em Educação Infantil e desenvolvimento) - Instituto a Vez do Mestre, Universidade Candido Mendes, Rio de Janeiro, 2011. 
SOUZA, E. C. O uso de jogos eletrônicos como ferramenta pedagógica: análise do jogo Minecraft. 2018. 88 f. Dissertação (Mestrado em Metodologias para o Ensino de Linguagens e suas Tecnologias) - Universidade Norte do Paraná - UNOPAR, Londrina, 2018.

SOUZA, L. C. P.; CANIELLO, A. O potencial significativo de games da educação: análise do Minecraft. Comunicação \& Educação, v. 20, n. 2, p. 37-46, jul/dez 2015. 